\title{
Emma Gannagé, Patricia Crone, Maroun Aouad, Dimitri Gutas, Eckart Schütrumpf éds., The Greek Strand in Islamic Political Thought. Proceedings of the Conference held at the Institute for Advanced Study, Princeton, 16-27 June 2003
}

Beyrouth, Imprimerie catholique, coll. « Mélanges de l'Université Saint Joseph », LVII, 2004, 608 p.

\section{Hartmut Fähndrich}

\section{OpenEdition Journals}

\author{
Édition électronique \\ URL : http://journals.openedition.org/assr/3941 \\ DOI : 10.4000/assr.3941 \\ ISSN : $1777-5825$ \\ Éditeur \\ Éditions de l'EHESS

\section{Édition imprimée} \\ Date de publication : 1 décembre 2006 \\ Pagination : $115-283$ \\ ISBN : 2-7132-2124-2 \\ ISSN : 0335-5985
}

\section{Référence électronique}

Hartmut Fähndrich, «Emma Gannagé, Patricia Crone, Maroun Aouad, Dimitri Gutas, Eckart Schütrumpf éds., The Greek Strand in Islamic Political Thought. Proceedings of the Conference held at the Institute for Advanced Study, Princeton, 16-27 June 2003 », Archives de sciences sociales des religions [En ligne], 136 | octobre - décembre 2006, document 136-49, mis en ligne le 13 février 2007, consulté le 21 septembre 2020. URL : http://journals.openedition.org/assr/3941 ; DOI : https://doi.org/10.4000/assr. 3941

Ce document a été généré automatiquement le 21 septembre 2020.

(C) Archives de sciences sociales des religions 


\section{Emma Gannagé, Patricia Crone,} Maroun Aouad, Dimitri Gutas, Eckart Schütrumpf éds., The Greek Strand in Islamic Political Thought. Proceedings of the Conference held at the Institute for Advanced Study, Princeton, 16-27 June 2003

Beyrouth, Imprimerie catholique, coll. « Mélanges de l'Université Saint Joseph », LVII, 2004, 608 p.

\section{Hartmut Fähndrich}

1 Dans l'histoire de l'échange culturel qui a toujours accompagné les confrontations guerrières entre la rive nord et la rive sud de la Méditerranée, la transmission de la tradition grecque est certainement un des évènements les plus remarquables. Dans la doctrine conventionnelle, c'est dans la période des $\mathrm{VIII}^{\mathrm{e}}-\mathrm{XI}^{\mathrm{e}}$ siècles que «l'Empire arabe", (das arabische Reich, pour emprunter la célèbre expression de Julius Wellhausen) se transforme en califat universel, ajoutant à son arabité une grande partie de l'héritage pratique, philosophique et scientifique disponible dans la région, élargissant ainsi l'ampleur de son savoir et les outils méthodologiques qui vont lui servir pour consolider les bases intellectuelles de cet empire transformé.

2 Les chemins qu'a pris ce savoir pour entrer et contribuer à la formation de la civilisation islamique étaient doubles: les contacts quotidiens et directs des conquérants avec la population des régions conquises, et la traduction du grec en arabe - souvent par l'intermédiaire de l'araméen - d'un grand nombre d'œuvres écrites. Sont particulièrement célèbres, et connus, les domaines médicaux, pharmacologiques et 
philosophiques liés aux grands noms d'Hippocrate, Galien, Dioscoride, Platon, Aristote et bien d'autres dont les œuvres furent traduites dans le cadre de cette activité.

"Greek into Arabic ", d'après le fameux titre du livre de Richard Walzer (Greek into Arabic: Essays on Islamic Philosophy, Harvard University Press, 1962), un des grands spécialistes de ce domaine pendant la première moitié $\mathrm{du} \mathrm{xx}^{\mathrm{e}}$ siècle, est donc un des évènements intellectuels fondamentaux dans l'histoire $d u$ monde. Pour cette seule raison, toute étude solidement documentée est bienvenue parce que susceptible d'enrichir notre connaissance de cet échange et de ses effets. Le volume LVII de la collection si méritoire des Mélanges de l'Université Saint-Joseph à Beyrouth nous offre toute une gamme d'études jetant la lumière sur ce processus. L'intention des éditeurs de ce recueil de contributions d'un colloque de deux semaines (!) en 2003 à Princeton n'est, cependant, pas d'ajouter « seulement » à notre connaissance de ces traductions, mais d'aller plus loin et de rester, en même temps, plus spécifique. Plus de vingt articles s'intéressent à cet héritage grec dans la pensée politique musulmane.

4 Les premiers articles sont, en fait, consacrés à quelques questions fondamentales de la pensée politique grecque, par exemple le régime (im)parfait, le rôle du prophète ou du philosophe dans la cité ou la théologie politique, tandis que deux tiers des études analysent ces mêmes idées dans les œuvres des grands penseurs du monde musulman « classique ", al-Fârâbî, les Ikhwân as-safâ', Ibn Ruchd (Averroès) et Ibn Khaldûn.

5 Ce qui était perceptible pendant le colloque et qu'on retrouve dans ce recueil est essentiellement, comme le dit Patricia Crone dans son introduction, «the continuity of late antiquity as Islam », c'est-à-dire la façon dont le monde musulman est, en fait, une/ la continuation de l'Antiquité, du monde hellénistique.

6 Ce volume est un véritable trésor pour tous ceux que passionne la question fascinante de la formation de l'islam comme civilisation. 